\title{
The Parents Stress Level in Facing Children Study From Home in the Early of Covid-19 Pandemic in Indonesia
}

\author{
Ellya Susilowati ${ }^{1}$, Mira Azzasyofia ${ }^{2}$ \\ ${ }^{1,2}$ Bandung Polytechnic of Social Welfare, Indonesia \\ Email: ellya.susilowati@poltekesos.ac.id
}

\begin{abstract}
This research aimed to determine the stress level of parents facing children study from home at the early time of the enactment of COVID-19 social distance policy in Indonesia. The method was conducted using a survey through social media that was filled in by parents who had school-age children and were studying from home. The distribution and filling of questionnaires were conducted from March 31, 2020, to April 6, 2020. 236 respondents filled out the questionnaire, but after data cleaning processed only 223 respondents' data could be analyzed. The instrument used was the Perceived Stress Scale from Sheldon Cohen. The survey results indicate that the stress level of parents facing children study from home in the initial three weeks of social distance policy is 75.34 percent in the medium category, however there are 10.31 percent of respondents who have high-stress levels and 71.88 percent among them are women or mothers. High-stress levels are influenced, among others, by the inability of parents to guide learning, family health concerns, and family economic problems. This condition is likely to continue with the extension of the study from home period. For this reason, it is recommended that child social workers can provide online psychosocial services for parents who accompany children at home, such as family counseling, family therapy that parents and children can do, and increase family resiliency during the pandemic.
\end{abstract}

Keywords: Stress, Parents, Study From Home, Early Covid-19

\section{A. INTRODUCTION}

Coronavirus pandemic (COVID-19) since February 2020 has hit the world, and Indonesia is one of the countries affected by the spread of the COVID-19. The impact of this pandemic is affecting economic stability, social, and children's education in Indonesia is disrupted. Each country makes policies that refer to the World Health Organization (WHO) policies to save people from the COVID-19 pandemic. The Indonesian government responds to this pandemic as a public health emergency, so that it issues a large-scale social restriction policy - PSBB (socialdistance) as a policy that is considered effective for breaking the COVID-19 pandemic chain, namely all people to stay at home and stay at home minimize activities outside the home. The policy took effect on March 16, 2020, including in the field of education where there is a policy of closing schools temporarily and transferring the learning process to home (study from home). The closure of this school applies from kindergarten to tertiary levels to implement learning at home. Initially, the policy only applied in areas where there were many positive cases of COVID-19 in five regions namely DKI Jakarta, West Java, DI Yogyakarta, East Java, 
and West Kalimantan. Then the policy was applied to all provinces in Indonesia. Based on data from UNESCO (2020), there are around 68 million students in Indonesia ranging from the level of early childhood education (PAUD) to Higher Education affected by learning policies at home.

The home learning system during the COVID-19 pandemic emergency was regulated by the Minister of Education circular No. 4 of 2020 on March 24, 2020, namely: a) Learning from Home through online/distance learning: b) focused on life skills education, including the Covid-19 Pandemic: c) Learning activities and tasks from home vary according to interests and the availability of learning facilities at home: and 4) Evidence or products of learning activities are assessed qualitatively (Makarim, 2020). The learning system requires active guidance from parents, while parents have been accustomed to hand over educational tasks to educational institutions.

The implementation of learning at home is a barrier not only for teachers and students but also for parents. Especially parents who are also implementing work at home. Since the home learning system was put in place, many parents have complained about the home learning system because it adds to their burden in the current pandemic. This was also as reported by Kompas.com on March 18, 2020, about "curhat Emak-Emak Di Depok soal Belajar di Rumah Sampai Bikin Stress (venting to Mother in Depok about Learning at Home Until Stress)". Most parents are not accustomed to assisting children learning at home, especially mothers who work outside the home. In addition, there are also parents who have limitations in assisting children's learning at home due to the low level of parental education, the limitations of the use of information technology tools. Andrew et al. (2020), in his research revealed that mothers pursue more domestic work and take care of children throughout the day during Pandemic COVID-19 than fathers. Men or fathers spend more time working from home than helping their wives or partners take care of children and do domestic work.

Other problem situations at the beginning of the COVID-19 pandemic, were the reporting and information about COVID-19 both through social and cellular media that were troubling, limited fulfilment of basic needs, the threat of reduced family finances, limited personal protective equipment and the uncertainty situation for the end of the pandemic. The issue also occurs during an emergency situation which can cause fear, anxiety and stress (Cacciatore et al., 2011; Morse, 2013). Stress in the elderly can cause negative emotional reactions and have a direct effect on health and can increase deterioration in people's quality of life (Aracena et al., 2016).

Sherwood in Windish (2016) said that stress is a psychological response from the body to several types of stress or stressful situations. The stressors that trigger the stress response are physical stressors (operating trauma, intense heat or cold); chemical stressors (reduced oxygen supply); physiological stressors (strenuous exercise, shock, pain); psychological and emotional stressors (anxiety, fear, and sadness); and stressors from social pressures (personal conflicts, lifestyle changes). Changes in children's learning policies at home can cause stress for parents because 
this is a social stress stressor where lifestyles become changed according to the pandemic COVID-19.

Based on this background the research team was interested in knowing the level of stress of parents who had children learning at home in the early days of the COVID-19 pandemic. High levels of stress will be able to disrupt the immune system (Larasati, 2016; Maddock \& Pariante, 2001). For this reason, stressful management and management at the present time is needed by everyone. This survey also aims to provide solutions for parents to cope with the stress they experience through social work interventions. The role of social workers during the pandemic is certainly needed on all fronts, including in helping stressed parents so that it will affect parenting and the actions of parents in educating children during this pandemic.

\section{B. METHOD}

This study uses descriptive research methods with a quantitative approach. The data collection technique is done by survey method. The survey was conducted by distributing questionnaires through various social media to be filled in by parents who have school-age children and are studying at home (study from home) ranging from kindergarten to universities. The distribution and filling of the questionnaire were conducted from March 31, 2020, to April 6, 2020. The results of this survey were responded by 236 respondents who filled out the questionnaire, but after cleaning the data only 223 respondents' data could be processed.

The instrument used in this survey is the Perceived Stress Scale (PSS) proposed by Cohen, where there are 14 question items consisting of seven questions related to seven stress factors and seven questions related to coping factors ( $\mathrm{Wu} \&$ Amtmann, 2013; Santiago et al., 2019). Cohen in Wu \& Amtmann (2013) argues that this PSS instrument is used to measure the stress level of the respondent's perspective and is designed to assess how things are unexpected and which can be controlled by someone in assessing their life. Data processing and analysis were carried out using the SPSS version 25 program.

This survey still has limitations where coverage of the survey area in Indonesia is not a top priority in the collection of questionnaires so that the results of this questionnaire only describe the level of stress experienced by parents who were respondents of this survey without being able to see the characteristics of the area of residence of the respondent.

\section{RESULT AND DISCUSSION}

\section{Result}

\section{Characteristics of Respondents}

The results of this survey discuss the characteristics of respondents and the perceived stress scale (PSS) of 223 parents who were respondents. Of the 223 parents who were respondents, 21.08 per cent were male and 78.92 per cent were female. As many as 51.12 per cents of respondents were aged 31-40 years, and 52.91 per cent had a Bachelor's education background, and 70.40 per cent of respondents said they 
were working. As many as 34.98 per cent of respondents have school-age children who are attending elementary school (SD), while 29.15 per cent are parents of children who are educating at the kindergarten level. In detail the level of education of the respondent's children can be seen in the following figure 1 :

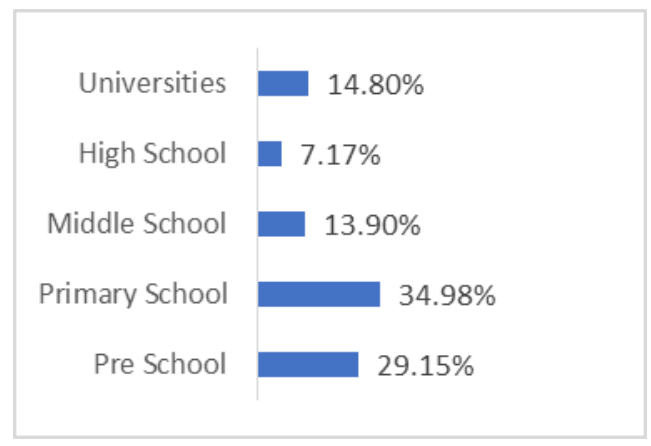

\section{Figure 1. Educational Level of Children from Questionnaire Respondents}

\section{Children's Learning Media at Home}

Minister of Education Decree No. 4 of 2020 about the home study is done online/remotely. Distance learning tools used are cellphones/tablets, laptops/computers/PCs, books and others. The results of a survey on the use of learning tools at home 64.62 per cent of respondents with children who were educated in kindergartens (TK) and 46.15 per cent of respondents with children who were educated in elementary schools (SD) answered books as a tool that is often used as a learning medium at home. In detail the use of learning tools is illustrated in the following figure:

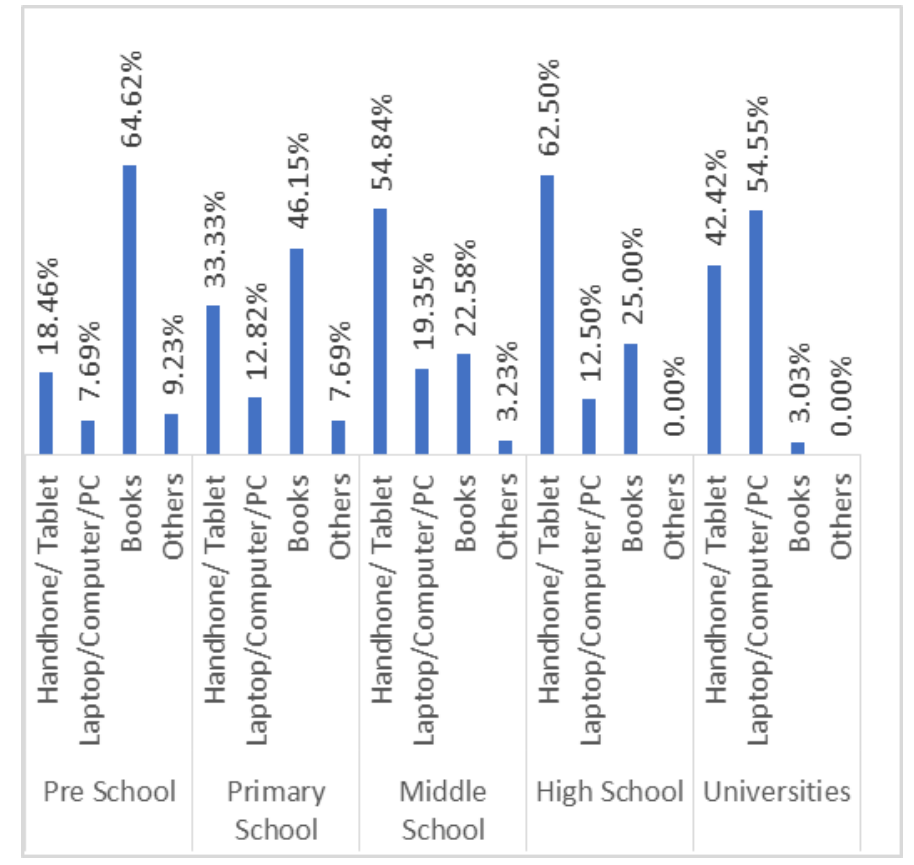

Figure 2. Use of Learning Tools at Home Based on Education Level

Meanwhile, 54.84 per cent of respondents with children who were attending junior high school and 62.50 per cent of respondents with children who were 
attending high school claimed that the learning tools often used were Cellphones/Tablets. For the use of online media or online platforms used by children in home learning activities, 56.50 per cent of parents answered that their children use Whatsapp as a learning medium and as a medium of communication with teachers or instructors.

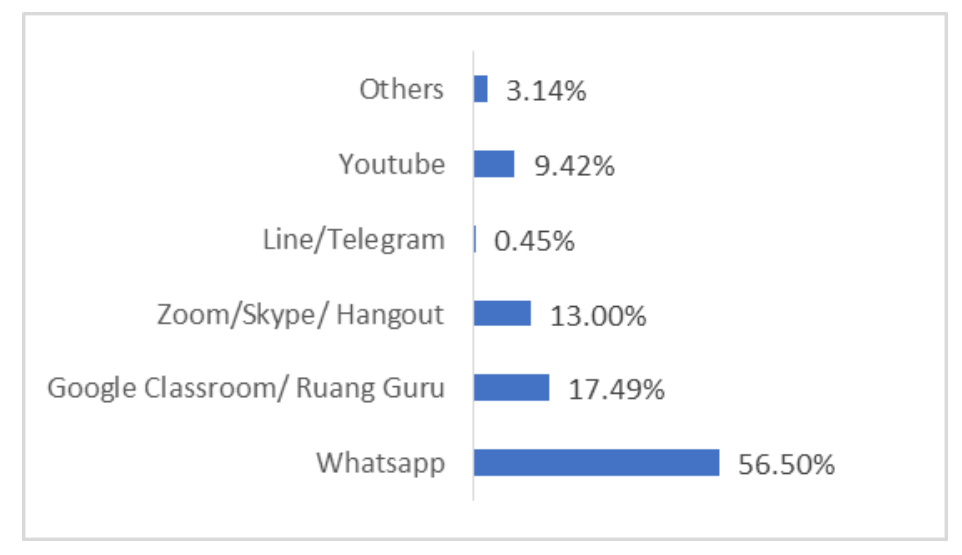

Figure 3. Online Media/Online Learning Platform at Home

\section{Parents' Concerns}

In this survey, parents were also asked about the worries they felt during their study at home. Some of the concerns parents felt during their study at home in the early days of the COVID-19 pandemic were related to assignments given from school, difficulties facing child learning, children's education, family health and family finances. Most parents do not feel that the school assigns a lot of tasks to their children, only 37.67 per cent of parents who feel that the school gives a lot of tasks to their children. As many as 37 per cents of parents who feel schools give a lot of work to children are parents of children who are attending elementary school.

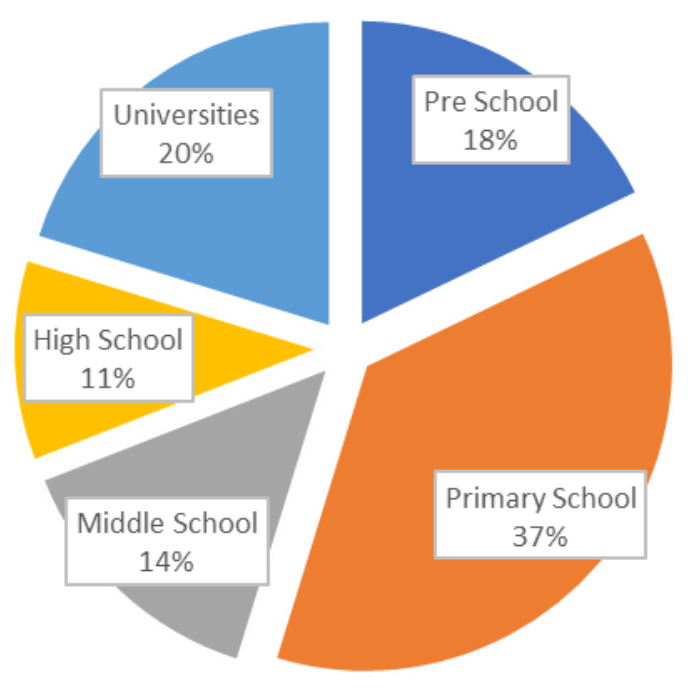

Figure 4. Provision of Many School Tasks Based on Children's Education Level 
Difficulties or obstacles with children learning at home are felt by 52.47 per cent of parents. There are more female parents (mothers) who feel they have obstacles with children learning at home compared to male parents (fathers). In addition, barriers are more felt by parents who have children who are attending kindergarten and elementary school.

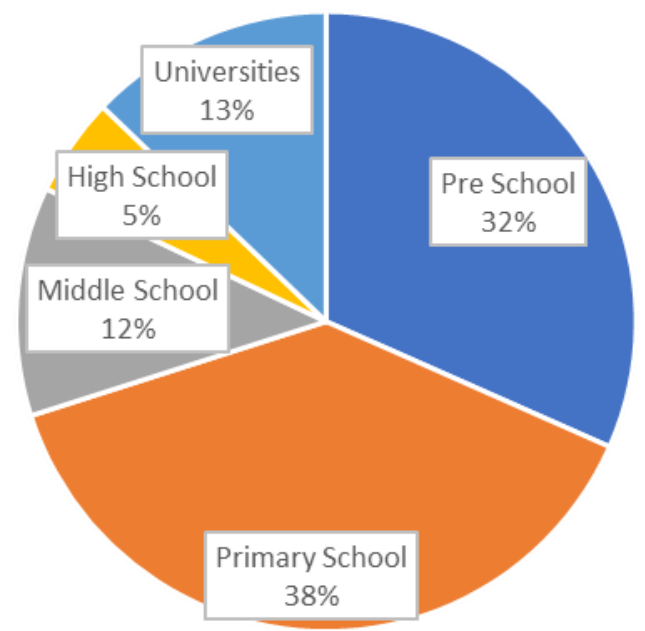

\section{Figure 5. Parents Have Barriers When Children Learn at Home Based on Children's Education Level}

In addition, there is 66.82 per cent of parents who become respondents have concerns about their child's current education. However, this concern is not felt by parents who have children who have a high school education, only 43.75 per cent of parents with children who have high school education who feel they have concerns about children's education.

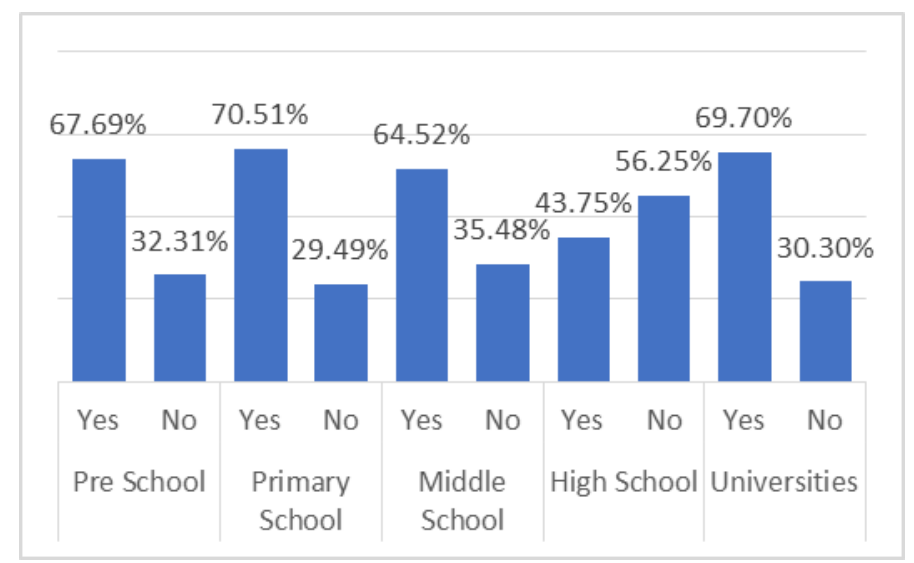

\section{Figure 6. Parents' Concerns About Children's Education Based on Children's Education}

Pandemic Covid-19, making almost all parents claim to have concerns about the health condition of the family, there are 80.27 per cent of parents who have concerns about this. Meanwhile, there are 56.05 per cent of parents who claim to have concerns about the current economic conditions of their families. Male parents (Fathers) tend to have more concerns about the economic condition of the family, as 
many as 70.21 per cent of male parents (Fathers) have concerns about their current family conditions, while for female parents (Mothers), there is 52.27 per cent who worried about the economic condition of the family.

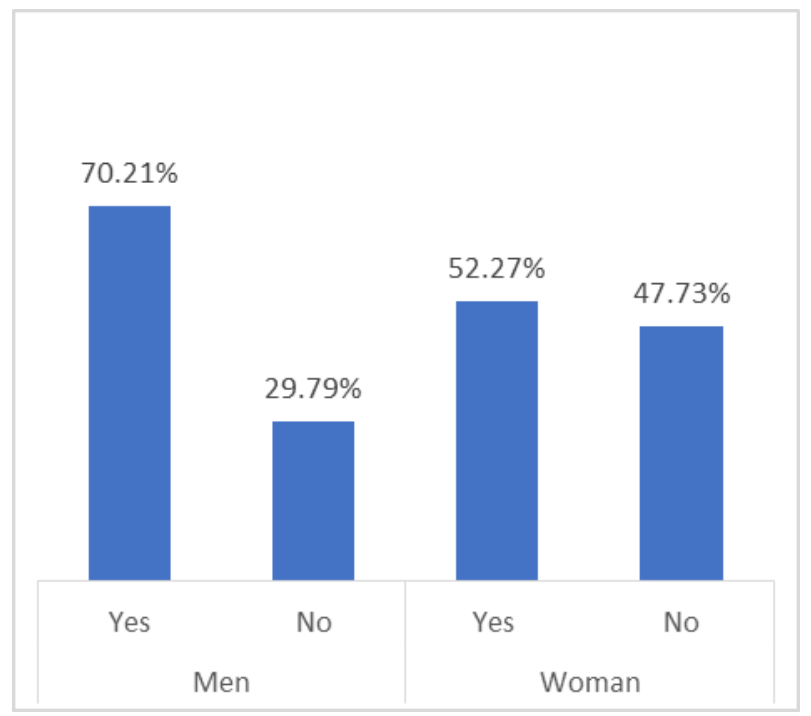

Figure 7. Parents' Concerns About Family Economic Conditions Based on Gender of Parents

\section{Parental Stress Level}

Stress levels of children's parents who are studying at home are divided into three categories namely high, medium, and low categories. The results of data processing using SPSS 25 obtained the following results:

Table 1 Parent Stress Levels in the Last One Month $(n=223)$

\begin{tabular}{|l|c|c|}
\hline \multicolumn{1}{|c|}{ Level of Stress } & Frequency (f) & Percent (\%) \\
\hline Low & 32 & 14.35 \\
\hline Middle & 168 & 75.34 \\
\hline High & 23 & 10.31 \\
\hline Total & $\mathbf{2 2 3}$ & $\mathbf{1 0 0 . 0}$ \\
\hline
\end{tabular}

Source: Processed Research Data, 2020

Based on table 1 above it can be seen that 75.34 per cent of parents experience moderate stress, and 10.31 per cent experience high stress. While 14.35 per cent experienced low-stress levels.

If related to gender, it can be seen that 71.88 per cent of respondents who experience high-stress levels are women as shown in the figure below: 


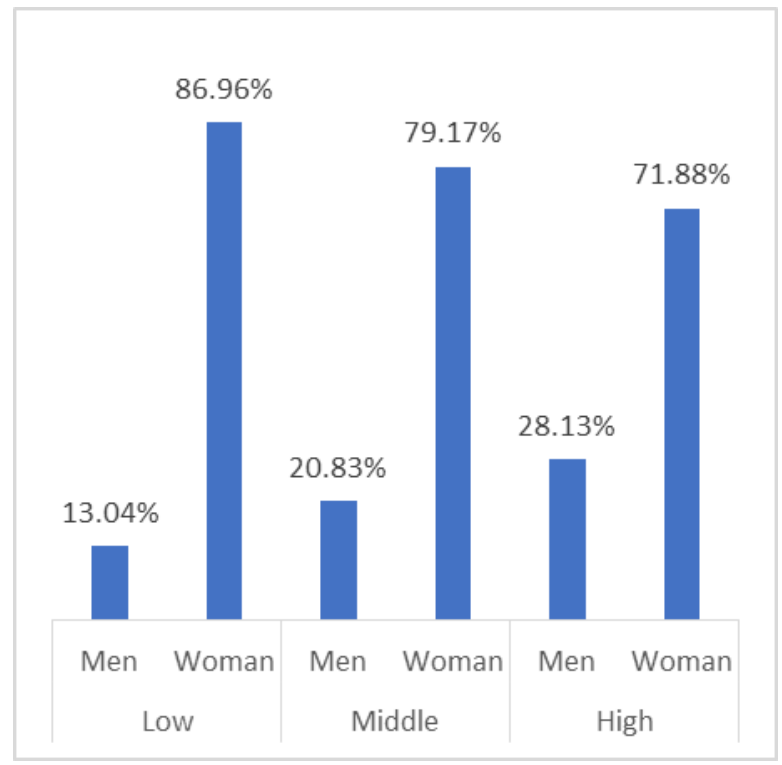

Figure 8. Parental Stress Levels Based on Gender of Parents

In addition, those who have high-stress levels, 73.91 per cent of them are those who find it difficult or have obstacles with their children studying at home as it is today. Of those who have high-stress levels, 78.26 per cent of them have concerns about their children's education and have concerns about their family's current economy. Meanwhile, 86.96 per cent of respondents who have high-stress levels have concerns about the health of their family at this time.

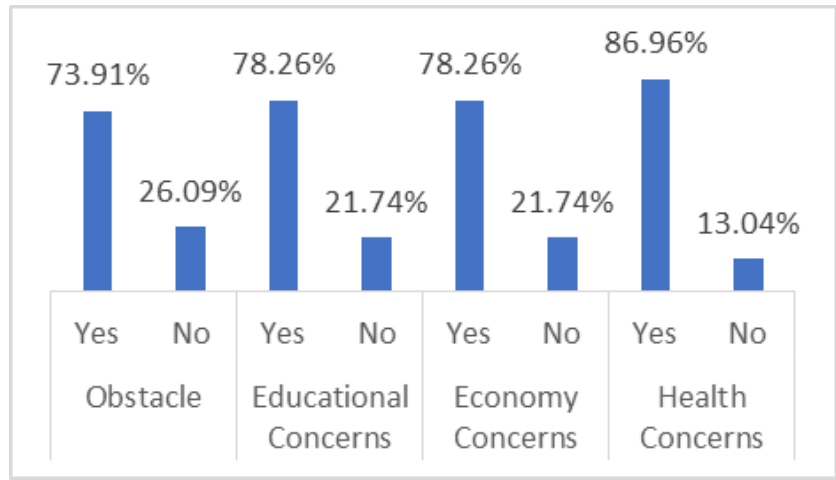

Figure 9. Characteristics of Parents with High-Stress Levels Based on Obstacles and Concerns Perceived in the Last One Month

\section{Discussion}

The survey results indicate that the stress level of parents who have children learning at home at the start of the COVID-19 pandemic shows at a moderate level of 75.34 per cent. However, there is 10.31 per cent of respondents who have high-stress levels. This condition can be analyzed as follows:

\section{The burden of Parents During the Pandemic COVID-19}

The majority of respondents who were respondents in this survey (70.40 per cent) were working women, aged between 31 and 40 years and had an 
undergraduate education background. Based on age groups, they are productive age and age groups that prioritize careers at work (Newman \& Newman, 2006). The results of the social demographic survey of the impact of COVID-19 showed that 43 per cent of the population with a bachelor's education background during the COVID-19 pandemic were busy WFH (BPS, 2020).

From this situation, it is possible that parents who have school children at the beginning of the COVID-19 pandemic in Indonesia are at moderate stress levels because they have to divide their time between work from home (WFH) and accompany children to learn from home at the same time. Some school rules about learning at home in elementary school children are children doing assignments through book guides and then the results of their work are conveyed to teachers assisted by parents through WhatsApp. This situation can lead to conflict for parents, especially women who are confronted between WFH with the assistance of children learning at home. This is as shown in Figure 9 that women have higher stress levels compared to men. This condition is also compounded by the increasing burden of household care, where all family members gather at home who have to get services. These tasks are more burdened to women (Andrew et al., 2020).

\section{Obstacles in Accompanying Children to Learn at Home}

The survey results show that barriers are more felt by parents who have children who are attending kindergarten and elementary school, and this is more felt by women (mothers). Kindergarten and elementary school children need more parental guidance in dealing with learning at home than middle and high school children. The most widely used learning media is the learning module book, including assignments that children must do and then submit it to the teacher. This results in the level of dependence of children on parents are quite high. While working parents are accustomed to handing over education to educational institutions, including to study additional subjects accustomed to being guided by tutors. Under these conditions, parents must also help to read and help send assignments to teachers via WhatsApp as revealed by the survey results.

The situation of learning at home during the COVID-19 pandemic is good for parents who have children learning at home also cause stress effects on parents. The results of a survey conducted by the Indonesian Tunas Cilik Foundation (2020) revealed that 1 out of 4 parents do not have teaching materials, do not have supporting tools, and do not have time to accompany children (YTCI, 2020). This obstacle to accompanying learning is also possible in families who have more than one school child so that they have more burdens to accompany the child.

\section{Concerns facing the Pandemic COVID-19}

Since the COVID-19 pandemic policy in which family members live at home, including children, there has been some concern for parents as the survey found. Some of these concerns are: (1) Many tasks are given from schools, 37 per cent of respondents answered that many tasks are given from schools, especially to 
elementary school children. Parents feel overwhelmed by the task of children, because parents, especially mothers have domestic tasks, WFH is quite timeconsuming. This condition can result in the child lacking in the quality of children's education and can affect the stunted growth and development of the child; (2) Difficulty facing children to learn, because parents lack mastering learning modules including how to deliver learning material. The survey results also showed that there were parents who did not master communication technology so that it was influential in assisting children's learning; 3) Family health. This COVID-19 pandemic has also influenced parents about how to maintain family health, so parents also need to pay attention to the health of family members to comply with health protocols. This condition also affects the stress level of parents. The description of the pandemic in Wuhan city at the time of the pandemic became a frightening reference. That concern is also compounded by issues of threats to the limitations of food logistics: 4) Family finances. The results of the survey in the third week at the start of the implementation of the PSBB policy where all activities at home have also affected the disruption of the family economy. This resulted in 10.31 per cent of parents who had high stress. This was also proven by the results of the BPS survey that there was a decrease in family income as a result of COVID-19.

If the condition is not resolved by the family it will cause psychosocial problems for parents and affect the care that should be carried out by parents (Pilarz \& Hill, 2017). This condition can also affect family immunity, which at the time of the COVID-19 pandemic needs to always be taken care of family health (Venkatesh et al., 2020). At this time family resilience or resilience efforts are needed to deal with situations of burnout, the possibility of conflict between family members and there must be no issues related to violence both emotionally, physically on children.

\section{CONCLUSION}

The social changes from the COVID-19 pandemic have been felt by parents who have school-age children and are studying at home in the initial three weeks of the COVID-19 policy in Indonesia which has caused moderate levels of stress. However, there is 10.31 per cent of respondents who have high-stress levels, where 71.88 per cent of them are female parents or mothers. Based on the results of the study, the role of social workers is needed to be able to help parents overcome the stress levels they experience when teaching children at home during the current COVID-19 pandemic.

Child social workers can provide online psychosocial services for parents who accompany children at home, such as family counselling, family therapy that parents and children can do, and increase family resilience during COVID-19.

\section{ACKNOWLEDGEMENT}

Thank you to the Bandung Social Welfare Polytechnic Research Center for supporting this survey. 


\section{REFERENCES}

1. Akiyama, T., Horie, K., Hinoi, E., Hiraiwa, M., Kato, A., Maekawa, Y., Takahashi, A., \& Furukawa, S. (2020). How does spaceflight affect the acquired immune system? In npj Microgravity. https://doi.org/10.1038/s41526-020-0104-1

2. Andrew, A., Cattan, S., Dias, M. C., Farquharson, C., Kraftman, L., Krutikova, S., ... \& Sevilla, A. (2020). How are mothers and fathers balancing work and family under lockdown?". Institute for Fiscal Studies.

3. Aracena, M., Gómez, E., Undurraga, C., Leiva, L., Marinkovic, K., \& Molina, Y. (2016). Validity and reliability of the parenting stress index short form (PSI-SF) applied to a chilean sample. Journal of Child and Family Studies, 25(12), 3554-3564. doi: $\underline{\text { http://dx.doi.org/10.1007/s10826-016-0520-8 }}$

4. Cacciatore, J., Carlson, B., Michaelis, E., Klimek, B., \& Steffan, S. (2011). Crisis intervention by social workers in fire departments: An innovative role for social workers. Social Work, 56(1), 81-8. Retrieved from https://search.proquest.com/docview/1008248884?accountid $=50790$

5. Central Bureau of Statistics. (2020). Hasil Survei Sosial Demografi Dampak Covid-19. Katalog 4101039.

6. Circular of the Minister of Education of the Republic of Indonesia Number 4 of 2020 on March 24, 2020.

7. Ghosh, S., \& Verma, K. (2018). Stress and its effect on noncommunicable disease: An insight. Journal of Social Health and Diabetes, 6(1), 15-21. doi: http://dx.doi.org/10.4103/JSHD.JSHD 3217

8. Kompas. (2020). Curhat Emak-Emak di Depok Soal Belajar dari Rumah Sampai Bikin Stress. $\quad$ Retrieved from https://www.kompas.com/edu/read/2020/03/18/122037771/curhat-emak-emakdi-depok-soal-belajar-dari-rumah-sampai-bikin-stres

9. Larasati, R. (2016). Pengaruh Stres pada Kesehatan Jaringan Periodontal. Jurnal Skala Husada: The Journal of Health, 13(1), 81-89.

10. Maddock, C., \& Pariante, C. M. (2001). How does stress affect you? An overview of stress, immunity, depression and disease. In Epidemiologia e Psichiatria Sociale. doi: https://doi.org/10.1017/S1121189X00005285

11. Morse, W. C. (2013). Crisis Intervention in Residential Treatment: The Clinical Innovation of Fritz Redl. New York: Routlege.

12. Newman \& Newman (2006). Development Throught Life. Thomson Wadworth.

13. Notten, N., Grunow, D., \& Verbakel, E. (2017). Social policies and families in stress: Gender and educational differences in work-family conflict from a european perspective. Social Indicators Research, 132(3), 1281-1305. doi: http://dx.doi.org/10.1007/s11205-016-1344-z

14. Pilarz, A. R., \& Hill, H. D. (2017). Child-care instability and behavior problems: Does parenting stress mediate the relationship?. Journal of Marriage and Family, 79(5), 1353-1368. doi: http://dx.doi.org/10.1111/jomf.12420 
15. Santiago, P. H. R., Roberts, R., Smithers, L. G., \& Jamieson, L. (2019). Stress beyond coping? A Rasch analysis of the Perceived Stress Scale (PSS-14) in an Aboriginal population. PloS one, 14(5), e0216333. https://doi.org/10.1371/journal.pone.0216333

16. UNESCO. (2020, June 23). Education: From disruption to recovery. Retrieved from https://en.unesco.org/covid19/educationresponse

17. Venkatesh, H. N., Ravish, H., Silvia, C. W. D., \& Srinivas, H. (2020). Molecular signature of the immune response to yoga therapy in stress-related chronic disease conditions: An insight. International Journal of Yoga, 13(1), 9-17. https://eresources.perpusnas.go.id:2116/10.4103/ijoy.IJOY 8218

18. Wu, S. M., \& Amtmann, D. (2013). Psychometric Evaluation of the Perceived Stress Scale in Multiple Sclerosis. ISRN Rehabilitation, Volume 2013. doi: http://dx.doi.org/10.1155/2013/608356.

19. Waisbrod, N., Buchbinder, E., \& Possick, C. (2012). In-home intervention with families in distress: Changing places to promote change. Social Work, 57(2), 12132.

Retrieved

from https://search.proquest.com/docview/1039539246? accountid $=50790$

20. Windish, Lance Scott. (2016). "Homeschooling Parent Stress Levels and Its Association With the Mental and Physical Health of Their Children". Theses and Dissertations (All). 1390. http://knowledge.library.iup.edu/etd/1390 